\title{
PENGARUH MODEL PEMBELAJARAN KOOPERATIF STAD BERBANTUAN MIND MAP TERHADAP HASIL BELAJAR IPA DAN SELF EFFICACY SISWA KELAS VIII SMP
}

\author{
Ni Putu Indah Kumala Sari ${ }^{1}$, I B. Putu Arnyana ${ }^{2}$, I B. Putu Mardana ${ }^{3}$ \\ ${ }_{1,2,3}$ Prodi S2 Pendidikan IPA, Jurusan Pendidikan IPA, Fakultas Matematika dan Ilmu \\ Pengetahuan Alam, Universitas Pendidikan Ganesha \\ Singaraja, Indonesia \\ E-mail: indahkumlasari3107@gmail.com,putu.arnyana@pasca.undiksha.ac.id, \\ putu.mardana@undiksha.ac.id
}

\begin{abstract}
ABSTRAK
Penelitian ini bertujuan (1) mendeskripsikan perbedaan hasil belajar IPA dan self efficacy siswa kelas VIII SMP yang menggunakan model pembelajaran kooperatif STAD berbantuan mind map dan model pembelajaran langsung, (2) medeskripsikan perbedaan hasil belajar IPA siswa kelas VIII SMP yang menggunakan model pembelajaran kooperatif STAD berbantuan mind map dan model pembelajaran langsung, serta (3) mendeskripsikan perbedaan self efficacy siswa kelas VIII SMP yang menggunakan model belajar kooperatif STAD berbantuan mind map dan model pembelajaran langsung. Fokus masalah penelitian ini adalah pengaruh model pembelajaran kooperatif STAD terhadap hasil belajar dan self efficacy siswa. Jenis penelitian ini merupakan eksperimen semu dengan rancangan non equivalent pretestposttest control group design. Populasi dalam penelitian ini adalah seluruh siswa pada kelas VIII SMP Negeri 2 Kuta Selatan yang terdiri atas 30 siswa. Pengambilan sampel penelitian berdasarkan teknik group random sampling. Data dalam penelitian ini berupa skor hasil belajar IPA siswa dan skor self efficacy yang dianalisis menggunakan uji Multivariate Analysis of Variance (MANOVA). Hasil penelitian menunjukkan bahwa (1) terdapat perbedaan hasil belajar IPA dan self efficacy siswa yang menggunakan model pembelajaran kooperatif STAD berbantuan mind map dan model pembelajaran langsung, (2) terdapat perbedaan hasil belajar IPA siswa yang belajar dengan model kooperatif STAD berbantuan mind map dan model pembelajaran langsung, (3) terdapat perbedaan self efficacy siswa yang belajar dengan model kooperatif STAD berbantuan mind map dan model pembelajaran langsung.
\end{abstract}

Kata kunci: model pembelajaran kooperatif STAD berbantuan mind map, hasil belajar IPA dan self efficacy

\begin{abstract}
This study aims to (1) describe the difference of learning outcomes of science and self efficacy of grade VIII junior high school students using cooperative learning model of STAD assisted by mind map and direct learning model, (2) to describe the difference of learning outcomes of science students of grade VIII of junior high school using cooperative learning model STAD assisted by mind map and direct learning model, and (3) to describe the difference of self efficacy of grade VIII SMP students using cooperative learning model of STAD assisted by mind map and direct learning model. The focus of this research problem is the influence of STAD cooperative learning model on student learning outcomes and self efficacy. This type of research is a quasi-experimental non-equivalent pretest-posttest control group design. The population in this study were all students in grade VIII of SMP Negeri 2 Kuta Selatan consisting of 30 students. The research sample was taken based on group random sampling technique. The data in this research are the scores of students' science learning outcomes and self efficacy scores analyzed using the
\end{abstract}


Multivariate Analysis of Variance (MANOVA) test. The result of the research shows that (1) there are differences of learning outcomes of science and self efficacy of students using cooperative learning model of STAD assisted by mind map and direct learning model, (2) there is difference of learning result of science student learning with cooperative model of mind map-assistedSTAD and model direct learning, (3) there are differences in selfefficacy of students who learn with the STAD cooperative model and direct learning models.

Keywords: mindmap-assisted STAD cooperative learning model, science learning outcomes and self-efficacy

\section{PENDAHULUAN}

Ilmu pengetahuan dan teknologi semakin berkembang pesat dari waktu ke waktu. Bangsa yang tidak ingin tertinggal dalam penguasaan ilmu pengetahuan dan teknologi harus mempersiapkan Sumber Daya Manusia (SDM) yang berkualitas. Untuk meningkatkan kualitas SDM diperlukan pula adanya peningkatan mutu pendidikan. Berdasarkan undang-undang Sisdiknas No. 20 Tahun 2003 Bab I, pendidikan adalah usaha sadar dan terencana untuk mewujudkan suasana belajar dan proses pembelajaran agar peserta didik secara aktif mengembangkan potensi dirinya untuk memiliki kekuatan spiritual keagamaan, pengendalian diri, kepribadian, kecerdasan, akhlak mulia, serta keterampilan yang diperlukan dirinya, masyarakat, bangsa dan negara. Untuk dapat meningkatkan kualitas pendidikan suatu bangsa, guru sebagai tenaga pendidik memegang peranan penting dalam keberhasilan suatu pendidikan.Berdasarkan data dalam Education For All (EFA) Global Monitoring Report 2011, The Hidden Crisis, Armed Conflict and Education yang dikeluarkan Organisasi Pendidikan, Ilmu Pengetahuan, dan Kebudayaan Perserikatan BangsaBangsa (UNESCO) yang diluncurkan di New York pada tahun 2011, indekspembangunan pendidikan atau Education Development Index(EDI) berdasarkan data tahun 2008 adalah 0,934. Nilai itu menempatkan Indonesia di posisi ke-69 dari 127 negara di dunia. Di Asia, Indonesia berada pada peringkat ke-34 masih tertinggal dari Brunei Darusalam.Berdasarkan penilaian oleh TIMSS (The Trends International Matemathics and Science Study) yang merupakan organisasi yang bergerak dalam bidang penilaian dan pengukuran pendidikan yang berkedudukan di Belanda pada tahun 2011, dari 42 negara siswa-siswa di Indonesia masih menempati urutan ke-38 untuk matematika dan ke-40 untuk sains. Sedangkan menurut PISA (The Programme for International Student Assesmennt) yang meneliti aspek membaca, sains dan matematika, Indonesia menempati urutan ke-64 dari 65 negara untuk kemampuan literasi sains.

Berdasarkan pengamatan secara nyata di lapangan, proses pembelajaran di sekolah masih banyak yang tidak melibatkan siswa, sehingga siswa kurang kreatif masih banyak guru yang menggunakan model pembelajaran yang konvensional dengan menggunakan metode ceramah dimana guru sebagai pusat informasi menerangkan materi dan siswa duduk dengan manis mendengarkan dan mencatat materi yang disampaikan oleh guru, sehingga siswa menjadi pasif dan tidak kreatif, karena tidak ada kesempatan bertanya, berdiskusi baik dengan guru maupun sesama siswa.Rendahnya hasil belajar siswa terbukti dari banyaknya siswa yang remidi pada setiap ulangan harian untuk mencapai nilai KKM. Hal ini juga terjadi di SMP Negeri 2 Kuta Selatan khususnya dalam mata pelajaran IPA.Selain permasalahan hasil belajar IPA, selfefficacy atau keyakinan diri siswa di SMP Negeri 2 Kuta Selatan juga dapat dikatakan rendah, hal ini dapat dilihat dari banyaknya siswa yang mencontek pada saat mengerjakan test dan kurangnya keyakinan diri siswa dalam menyampaikan pendapat apabila guru memberikan kesempatan siswa untuk menjawab 
permasalahan yang dilontarkan pada siswa khususnya dalam pembelajaran IPA.

Self efficacymerupakan kepercayaan seseorang terhadap kemampuannya untuk belajar atau menampilkan perilaku pada tahap tertentu (Bandura, 1997). Secara teoritis self efficacy berkembang seiring dengan perkembangan fisik dan akademis individu, hal ini dapat terjadi dengan baik apabila proses pembelajaran yang dialami siswa memberikan keleluasaan bagi siswa untuk menumbuhkembangkan kemandirian belajarnya.Salah satu model pembelajaran kooperatif yang dapat diterapkan untuk membantu mengembangkan dan mengoptimalkan hasil belajar IPA dan self efficacy siswa adalah model pembelajaran kooperatif.Dalam penerapannya pembelajaran kooperatif tipe STAD dapat diterapkan dengan berbantuan peta pikiran atau mind map agar lebih memantapkan pemahaman siswa pada suatu materi yaitu pada saat siswa melakukan diskusi dalam kelompok. Karena dengan membuat peta konsep berdasarkan pemahamannya sendiri siswa dapat lebih menguasai suatu materi. Mind map atau peta pikiran dapat diartikan sebagai suatu cara untuk mengorganisasikan danmenyajikan konsep, ide, tugas atau informasi lainnya dalam bentuk diagram radial-hierarkis non-Tinier.Mind map dapat dimanfaatkan untuk berbagai kepentingan, baik yang bersifat personal maupun kolaboratif. Khusus dalam konteks pembelajaran IPA mind map dapat digunakan untuk membantu siswa dalam memahami, mengorganisasikan dan memvisualisasikan materi dan aktivitas belajarnya secara kreatif dan atraktif.Dengan membiasakan siswa menggunakan teknik mind map (peta pikiran) ini dalam mencatat informasi pembelajaran yang diterimanya, tentu menjadikan mereka lebih aktif dan kreatif. Dengan demikian keyakinan diri siswa akanpengetahuannya akan lebih tinggi, sehingga siswa juga akan lebih yakin untuk mengerjakan soal evaluasi yang diberikan guru (Sudjiono, 2014).

Berdasarkan pemaparan di atas diyakini terdapat perbedaan Model Pembelajaran Kooperatif tipe STAD Berbantuan Mind Map dan Model Pembelajaran Langsung (DI) dalam meningkatkan hasil belajar siswa dan self efficacy khususnyapembelajaran IPA.

\section{METODE PENELITIAN}

Penelitian ini merupakan penelitian eksperimen semu (quasy experiment). Penelitian ini dikatakan penelitian eksperimen semu karena tidak semua variabel yang berpengaruh terhadap hasil penelitian dapat dikontrol dengan baik. Selain itu hal ini dilakukan karena proses randomisasi terhadap siswa yang telah dikelompokkan ke dalam kelas tertentu tidak mungkin dilakukan tanpa merusak tatanan kelas yang sudah ada.

Penelitian eksperimen semu digunakan untuk mengungkapkan hubungan sebab-akibat dengan cara melibatkan kelompok kontrol disamping kelompok eksperimen. Rancangan penelitian yang digunakan adalah non equivalent pretestpostest control group design. Rancangan ini dipilih karena dalam penelitian ini peneliti menggunakan kelas VIII yang ada di SMP Negeri 2 Kuta Selatan dan tidak memungkinkan untuk mengubah anggota kelas tersebut. Pada pelaksanaan penelitian, baikpretest maupun postest sama-sama dilakukan pada kelas eksperimen dan kelas control.

Populasi dalam penelitian ini adalah seluruh siswa kelas VIII SMP Negeri 2 Kuta Selatan tahun pelajaran 2017/2018 yang berjumlah 360 orang siswa yang terdistribusi dalam kelas-kelas yang homogen secara akademik. Secara keseluruhan kelas VIII di SMP Negeri 2 Kuta Selatan terbagi menjadi 10 kelas.

Sampel yang digunakan dalam penelitian ini dipilih secara representatif dengan menggunakan teknik probability sampling yaitu random sampling terhadap siswa kelas VIII SMP Negeri 2 Kuta Selatan. Setiap siswa kelas VIII memiliki peluang yang sama untuk dapat dipilih menjadi sampel.Berdasarkan hasil pengundian maka sampel yang digunakan untuk mewakili seluruh siswa kelas VIII di SMP Negeri 2 Kuta Selatan adalah kelas VIII.3dan kelas VIII.7 yang masing- masing kelas terdiri dari 36 orang siswa.

Metode pengumpulan data yang digunakan adalah tes. Hasil belajar IPA 
siswa diukur degan tes hasil belajar. Self efficacy siswa diukur dengan kuisioner self efficacy.

\section{HASIL DAN PEMBAHASAN}

\section{Hasil Penelitian}

Bagian ini mendeskripsikan distribusi frekuensi, perbandingan nilai rata-rata $(\mathrm{M})$, serta standar deviasi (SD) hasil belajar IPA dan Self Efficacy siswa kelompok eksperimen yang mengikuti pembelajaran dengan model pembelajaran kooperatif
STAD berbantuan mind map, dan kelompok kontrol yang mengikuti pembelajaran dengan model pembelajaran langsung atau direct interaction.

Hasil analisis deskriptif data hasil belajar IPA danself efficacy siswa dapat dilihat pada tabel di bawah ini.

Tabel 1. Hasil Analisis Deskriptif Data Pretest, Postest dan Gain Skor Hasil Belajar IPA Siswa Kelompok Kontrol dan Kelompok Eksperimen

\begin{tabular}{lcccccc}
\hline Statistik & \multicolumn{5}{c}{ Kelompok } \\
\cline { 2 - 7 } & \multicolumn{3}{c}{ Eksperimen } & \multicolumn{3}{c}{ Kontrol } \\
\cline { 2 - 7 } & $\begin{array}{c}\text { Pre- } \\
\text { Test }\end{array}$ & $\begin{array}{c}\text { Post- } \\
\text { Test }\end{array}$ & $\begin{array}{c}\text { Gain } \\
\text { Skor }\end{array}$ & $\begin{array}{c}\text { Pre- } \\
\text { Test }\end{array}$ & $\begin{array}{c}\text { Post- } \\
\text { Test }\end{array}$ & Gain Skor \\
\hline Mean & 38,58 & 71,2 & 0,53 & 32,95 & 62,95 & 0,44 \\
Std Deviasi & 8,21 & 7,89 & 0,095 & 6,89 & 5,36 & 0,091 \\
Varian & 67,41 & 62,22 & 0,009 & 47,35 & 28,69 & 0,008 \\
Minimum & 60 & 85,72 & 0,35 & 48,58 & 71,43 & 0,30 \\
Maksimum & 22,86 & 51,43 & 0,73 & 20 & 51,43 & 0,62 \\
\hline
\end{tabular}

Tabel 2. Hasil Analisis Deskriptif Data Self Efficacy Siswa

\begin{tabular}{lcccccc}
\hline \multirow{1}{*}{ Statistik } & \multicolumn{5}{c}{ Kelompok } \\
\cline { 2 - 6 } & \multicolumn{5}{c}{ Eksperimen } & \multicolumn{1}{c}{ Kontrol } \\
\cline { 2 - 6 } & Pre- & Post- & Gain & Pre- & Post- & Gain Skor \\
& Test & Test & Skor & Test & Test & \\
\hline Mean & 67,33 & 86,77 & 0,60 & 65,99 & 83,58 & 0,51 \\
Std Deviasi & 3,48 & 4,89 & 0,129 & 4,25 & 4,87 & 0,139 \\
Varian & 12,11 & 23,83 & 0,017 & 18,02 & 23,67 & 0,020 \\
Minimum & 73,72 & 95,43 & 0,32 & 74,29 & 91,43 & 0,22 \\
Maksimum & 60 & 76 & 1,86 & 60 & 73,72 & 0,73 \\
\hline
\end{tabular}

Selanjutnya dilakukan uji normalitas. Uji normalitas data dilakukan untuk menguji normal atau tidaknya sebaran data yang diperoleh. Uji normalitas dilakukan dengan statistika Kolmogorov Smirnov dan ShapiroWilk. Kriteria pengujannya adalah data memiliki sebaran yang berdistribusi normal jika angka signifikansi yang diperoleh lebih besar dari 0,05 dan dalam hal lain sebaran data tidak berdistribusi normal. Hasil ringkasan uji normalitas data untuk hasil belajar IPA dan self efficacy siswa dapat dilihat pada dibawah ini.

Tabel 3 Ringkasan Uji Normalitas Sebaran Data

\begin{tabular}{llccccccc}
\hline \multirow{2}{*}{ Model Pembelajaran } & \multicolumn{3}{c}{ Kolmogorov-Smirnov } & \multicolumn{4}{c}{ Shapiro-Wilk } \\
\cline { 3 - 9 } & $\begin{array}{c}\text { Statist } \\
\text { ic }\end{array}$ & Df & Sig. & $\begin{array}{c}\text { Statist } \\
\text { ic }\end{array}$ & Df & Sig. & $\begin{array}{c}\text { Distribusi } \\
\text { Data }\end{array}$ \\
\hline $\begin{array}{l}\text { Hasil } \\
\text { Belajar }\end{array}$ & Eksperimen & 0,122 & 36 & 0,197 & 0,967 & 36 & 0,356 & Normal \\
\cline { 2 - 9 } & Kontrol & 0,125 & 36 & 0,170 & 0,950 & 36 & 0,104 & Normal \\
\hline
\end{tabular}




\begin{tabular}{lllllllll}
\hline Self & Eksperimen & 0,110 & 36 & 0,200 & 0,976 & 36 & 0,617 & Normal \\
\cline { 2 - 9 } Efficacy & Kontrol & 0,135 & 36 & 0,093 & 0,947 & 36 & 0,085 & Normal \\
\hline
\end{tabular}

Berdasarkan ringkasan hasil uji normalitas sebaran data pada Tabel 3 dapat dilihat hasil belajar IPA memiliki angka signifikansi 0,356 pada kelompok eksperimen dan 0,104 pada kelompok kontrol, sedangkan self efficacy siswa memiliki angka signifikansi 0,617 pada kelompok eksperimen dan 0,085 pada kelompok kontrol.sehingga sebaran data hasil belajar belajar dan self efficacy baik pada kelompok kontrol yang belajar dengan model pembelajaran kooperatif STAD berbantuan mind map maupun kelompok kontrol yang belajar dengan model pembelajaran DI merupakan data yang berdistribusi normal.

Uji homogenitas varians merupakan uji yang digunakan untuk mengetahui homogen atau tidaknya data yang digunakan. Uji homogenitas data dilakukan dengan menggunakan Levene's Test of Equality of Error Variance. Teknik analisis dilakukan dengan menggunakan program SPSS-PC 22.0 for Windows. Data dinyatakan memiliki varian yang homogen apabila angka signifikansi lebih besar dari 0,05 ( $\mathrm{p}>$ 0.05).Berdasarkan hasil uji homogenitas varians tersebut dapat dilihat taraf signifikansi untuk data hasil belajar dan self efficacy siswa lebih besar dari 0,05. Taraf signifikansi untuk data hasil belajar siswa adalah 0,727 sedangkan taraf signifikansi untuk data self efficacy adalah 0,340 . Hal ini berarti varians data antar kelompok adalah homogen.

\section{Pembahasan}

Uji Kolinearitas bertujuan untuk mencari hubungan atau korelasi antara hasil belajar dan self efficacy siswa.Berdasarkan data yang disajikan diketahui bahwa nilai korelasi antara variabel hasil belajar dan self efficacy adalah 0,226. Nilai korelasi tersebut lebih kecil daripada 0,8 yang berarti bahwa kedua variabel tersebut tidak memiliki korelasi yang tinggi, sehingga analisis dapat dilanjutkan dengan uji MANOVA.

Berdasarkan deskripsi umum hasil penelitian, uji asumsi, dan uji hipotesis telah diketahui bahwa harga F untuk Pillai's Trace,Wilks 'Lambda, Hotteling's Trace, dan Roy's Largest Root memiliki nilai F sebesar 11,351 dengan signifikansi 0,00 . Nilai signifikansi tersebut lebih kecil dari 0,05 (p $<0,05$ ), hal tersebut berarti data penelitian yang diperoleh signifikan. Sehingga dapat dikatakan bahwa terdapat perbedaan hasil belajar IPA dan self efficacy siswa antara siswa yang belajar dengan menggunakan model pembelajaran kooperatif STAD berbantuan mind map dan model pembelajaran langsung (DI).

Hasil analisis test of between-subject effect diperoleh bahwa sumber pengaruh model pembelajaran terhadap hasil belajar IPA memiliki nilai $\mathrm{F}$ sebesar 17,982 dengan angka signifikansi 0,00 lebih kecil dari taraf signifikansi 0,05 . Hal tersebut berarti bahwa terdapat perbedaan rata-rata hasil belajar IPA siswa yang belajar dengan model pembelajaran kooperatif STAD berbantuan mind map dan siswa yang belajar dengan model pembelajaran langsung (DI). Hasil uji lanjut Least Significant Difference (LSD) menunjukkan nilai $\mu(\mathrm{i})-\mu(\mathrm{j})=0,09$ nilai tersebut lebih besar dibandingkan dengan batas nilai penolakannya yaitu $0,044(\mu(\mathrm{i})$ $\mu(j)>$ LSD), hal ini berarti skor rerata hasil belajar IPA siswa antara kelompok model pembelajaran kooperatif STAD berbantuan mind map dan model pembelajaran langsung (DI) berbeda signifikan pada taraf signifikan pada taraf signifikansi $5 \%$.

Berdasarkan analisis test of betweensubject effect diperoleh bahwa sumber pengaruh model pembelajaran terhadap self efficacy siswa memiliki nilai $\mathrm{F}$ sebesar 7,161 dengan angka signifikansi 0,009 lebih kecil dari taraf signifikansi 0,05 . Hal tersebut berarti bahwa terdapat perbedaan rata-rata self efficacy siswa yang belajar dengan model pembelajaran kooperatif STAD berbantuan mind map dan siswa yang belajar dengan model pembelajaran langsung (DI). Hasil uji lanjut Least Significant Difference (LSD) menunjukkan nilai $\mu(\mathrm{i})-\mu(\mathrm{j})=0,09$ nilai tersebut lebih besar dibandingkan dengan batas nilai penolakannya yaitu 0,062 
$(\mu(\mathrm{i})-\mu(\mathrm{j})>\mathrm{LSD})$, hal ini berarti skor rerata self efficacy siswa antara kelompok model pembelajaran kooperatif STAD berbantuan mind map dan model pembelajaran langsung (DI) berbeda signifikan pada taraf signifikansi $5 \%$.

\section{SIMPULAN DAN SARAN}

Berdasarkan hasil pembahasan tersebut dapat disimpulkan beberapa hal, diantaranya adalah Terdapat perbedaan hasil belajar IPA dan self efficacy siswa kelas VIII SMP yang menggunakan model pembelajaran kooperatif STAD berbantuan mind map dan model pembelajaran langsung. Terdapat perbedaan hasil belajar IPA sisa kelas VIII SMP yang menggunakan model pembelajaran kooperatif STAD berbantuan mind map dan model pembelajaran langsung). Terdapat perbedaan self efficacy siswa kelas VIII SMP yang menggunakan model pembelajaran kooperatif STAD berbantuan mind map dan model pembelajaran langsung.

Saran yang dapat disampaikan terkait dengan penelitian ini adalah Kepada guru IPA agar lebih meningkatkan lagi efektivitas penerapan model pembelajaran kooperatif STAD berbantuan mind map dalam proses pembelajaran,Dalam penerapan pembelajaran dengan menggunakan model pembelajaran kooperatif STAD berbantuan mind map, guru sebaiknya memperhatikan alokasi waktu pelaksanaan masing-masing tahapan.Pada saat mengkondisikan siswa menjadi kelompok, guru sebaiknya benarbenar memperhatikan kemampuan siswa dan Kepada para pemegang kebijakan dalam pendidikan, agar dapat menjadikan model pembelajaran kooperatif STAD berbantuan mind map sebagai alternatif untuk meningkatkan hasil belajar dan self efficacy siswa di sekolah.

\section{DAFTAR RUJUKAN}

Arnyana, I. B. P.2007. Dasar-Dasar Metodologi Penelitian. Universitas Udayana : Bagian Ilmu Faal Fakultas Kedokteran
Arnyana, I. B. P. 2007. Buku Ajar Strategi Belajar Mengajar Universitas Udayana: Bagian Ilmu Faal Fakultas Kedokteran

Aryati, Prasetyani. 2011. Pikologi Pendidikan. Surakarta: Badan Penerbit Universitas Muhammadiyah

Astiti, N. W. 2012. "Pengaruh Model Pembelajaran Kooperatif Tipe STAD dan Motivasi Prestasi terhadap Hasil Belajar IPS Siswa Kelas VII SMP Negeri 2 Semarapura". E-Jurnal Pascasarjana Undiksha. Vol.2, No.1.

Aseany, A, K, L,. 2011. "Pengaruh Model Pembelajaran Kooperatif Tipe Jigsaw Berbantuan Teknologi Informasi dan Komunikasi Terhadap Hasil Belajar Biologi ditinjau dari Motivasi Belajar Siswa SMA". Jurnal Penelitian Pascasarjana Undiksha. Volume 1, No. 2. http://oldpasca.undiksha.ac.id/ejournal/ Diunduh tanggal 20 April 2018

Bandura, A.1997. Social Foundation bof Tought and Action: A Social Cognitive Theory. New Jersey: Prentice-Hall, Inc

Bandura, A. 1997. Self-efficacy: The Exercise of Control. New York: W.H. FreemanCompany

Bandura, A,. \&Locke, E. A. (2003). "Negative self-efficacy and Goal effect ". Journal of Applied psychology. Volume 88, no 1 , (halaman 87-99). http://www.emory.edu/education/

Buzan, T dan Barry. 2008. Memahami Peta Pikiran. Bandung: Interaksara

Candiasa. 2010. Statistik Univariat dan Bivariat Disertai Aplikasi SPSS. Singaraja: Program Pascasarjana Universitas Pendidikan Ganesha.

Dahar, RW dan Liliasari. 1986. Interaksi Belajar Mengajar IPA. Jakarta: Universitas Terbuka Jakarta. 
Hake, R.R. 1999. "Analyzing Change/ Gain Score". http://www.physics.indiana.edu/

Hamalik, O. 2008. Proses Belajar Mengajar. Jakarta: Bumi Aksara

Jhonson, D. W., Jhonson, R. T. \& Stanne, M.B. 2000. "Cooperative Learning Methods: A Meta Analysis ".http://www.cooperation.org/pages/cl-methods.

Lantajo, J. T. 2017. "The Use of STAD Model in Teaching Chemistry: Its Effect to Students' Academic Performance". CEBU International Conference on Studies in Business, Management, Education and Law (SBMEL-17) Cebu (Philippines). Diakses di http://doi.org/ pada 25 Juni 2018

Madra, I K. 2012. "Pengaruh Model Pembelajaran Kooperatif Tipe Student Teams Achievemens Division terhadap Prestasi Belajar Kimia Ditinjau Dari Motivasi Berprestasi pada Siswa Kelas X SMA Negeri 1 Gianyar". E-Jurnal Pascasarjana Undiksha. Vol.1, No.1.

Marning, M. L. \& Lucking, R. 1991. "The What, Why and How of Cooperative Learning". Social Studies, Volume 82. (Diakses dari Questia Media America. Inc .https://www.questia.com/). Diunduh tanggal 20 April 2018

Nuaja, I K. 2011. "Pengaruh Model Pembelajaran Kooperatif Tipe STAD terhadap Prestasi Belajar Biologi Ditinjau dari Motivasi Belajar dan Kerja Siswa SMA". EJurnal Pascasarjana Undiksha. Vol.1, No.1.

Ocampo, R. O \& Ocampo, R. B .2015. "Effectiveness of Students' Team Achievement Division on Students' Attitude Towards Physics". Asia Pacific Journal of Multidisciplinary Research. Volume 3 No. 4 (halaman 112-117). Diakses www.apjmr.com pada 25 Juni 2018
Pervin, L. A., Cervone, D., dan John O.P. 2010. Psikologi Kepribadian : Teori dan Penelitian (edisi kesembilan). Jakarta : Kencana.

Rustaman, N. Et. Al. 2003. Strategi Pembelajaran Mengajar Biologi. Jakarta: Kencana Predana Media Group.

Santyasa, I. W. 2006. Pembelajaran inovatif: Model kolaboratif, basis proyek, dan orientasi NOS. Makalah. Disajikan dalam Seminar di Sekolah Menengah Atas SMA) Negeri 2 Semarapura, Universitas Pendidikan Ganesha, Singaraja, 27 Desember 2006

Schunck, D. H.(1995). Self- Efficacy and Education and Instruction. In J.E. Maddux Ed), Self Efficacy, Adaption and Adjusmen: Theory, Research and Application New York: Plenum

Slavin, R. E. 1995. Cooperative Learning Theory, Research and Practice. Second Edition. Boston: Allyn and Bacon

Slavin, R. E. 2008. Psikologi Pendidikan: Teori dan Praktik Edisi Kedelapan Jilid1. Jakarta : Indeks.

Sudijono. 2014. 'Pengaruh Mind Mapping Terhadap Peningkatan Efikasi Dari Matematika dan Prestasi Belajar Matematika Siswa SMP'. Disertasi Universitas Gajah Mada. http:// etd.repository.ugm.ac.id/

Sudjana, N. 2009. Penilain Hasil Proses Belajar Mengajar. Bandung: Remaja Rosdakarya

Sugiyono. 2013. Metode Penelitian Pendidikan Pendekatan Kuantitatif, Kualitatif, R\&D. Bandung: Alfabeta

Sugiyono. 2013. Statistika untuk Penelitian. Bandung: Alfabeta

Sund, Robert B. \& Leslie W. Trowbridge. 1973. Teaching Science By Inquiry in The Secondary School. Second edition. London: Charles E. Merrill Publishing Company. 
Suprijono, A.2009. Cooperative Learning Teori \& Aplikasi Paikem. Surabaya: Pustaka Pelajar

Syah, M. 1999. Psikologi Belajar. Jakarta: PT. Raja Grafindo Persada

Trianto. 2007. Model-model Pembelajaran Inovatif berorientasi Kontruktivistik. Jakarta : Prestasi Pustaka

Winkel, W. S.2005. Psikologi Pengajaran. Edisi Revisi. Jakarta: Raja Grasindo Persada

Woolfolk, A. E. 2004. Educatoinal psychology. New Jersey : Allyn \& Bacon

Yusuf, M. 2011. "The Impact of SelfEfficacy, Achievement Motivation, and Self- Regulated Learning Strategies on Student Academic Achievement. Procedia and Behavioral Sciences. Volume 15, halaman 2623-2626 http://sciencedirect.com/ Diunduh tanggal 20 April 2018 